\title{
Geographical information system and spatial-temporal statistics for monitoring infectious agents in hospital: a model using Klebsiella pneumoniae complex
}

Priscila Pinho da Silva ${ }^{1}$, Fabiola A. da Silva ${ }^{2,8}$, Caio Augusto Santos Rodrigues ${ }^{3}$, Leonardo Passos Souza ${ }^{3}$, Elisangela Martins de Lima ${ }^{4}$, Maria Helena B. Pereira ${ }^{5}$, Claudio Neder Candella ${ }^{2}$, Marcio Zenaide de Oliveira Alves ${ }^{4}$, Newton D. Lourenço ${ }^{3}$, Wagner S. Tassinari ${ }^{6,9}$, Christovam Barcellos ${ }^{7 *}$ and Marisa Zenaide Ribeiro Gomes ${ }^{1,4^{*}}$ (i) on behalf of Nucleus of Hospital Research Study Collaborators

\begin{abstract}
Background: The emergence and spread of antimicrobial resistance and infectious agents have challenged hospitals in recent decades. Our aim was to investigate the circulation of target infectious agents using Geographic Information System (GIS) and spatial-temporal statistics to improve surveillance and control of healthcare-associated infection and of antimicrobial resistance (AMR), using Klebsiella pneumoniae complex as a model.

Methods: A retrospective study carried out in a 450-bed federal, tertiary hospital, located in Rio de Janeiro. All isolates of K. pneumoniae complex from clinical and surveillance cultures of hospitalized patients between 2014 and 2016, identified by the use of Vitek-2 system (BioMérieux), were extracted from the hospital's microbiology laboratory database. A basic scaled map of the hospital's physical structure was created in AutoCAD and converted to QGis software (version 2.18). Thereafter, bacteria according to resistance profiles and patients with carbapenem-resistant $K$. pneumoniae (CRKp) complex were georeferenced by intensive and nonintensive care wards. Space-time permutation probability scan tests were used for cluster signals detection.
\end{abstract}

Results: Of the total 759 studied isolates, a significant increase in the resistance profile of $K$. pneumoniae complex was detected during the studied years. We also identified two space-time clusters affecting adult and paediatric patients harbouring CRKp complex on different floors, unnoticed by regular antimicrobial resistance surveillance.

Conclusions: In-hospital GIS with space-time statistical analysis can be applied in hospitals. This spatial methodology has the potential to expand and facilitate early detection of hospital outbreaks and may become a new tool in combating AMR or hospital-acquired infection.

\footnotetext{
*Correspondence: marisargomes@ioc.fiocruz.br; christovam.barcellos@icict.

fiocruz.br

${ }^{1}$ Laboratório de Genética Molecular de Microrganismos, Instituto

Oswaldo Cruz - Fundação Oswaldo Cruz, Avenida Brasil, 4365, Pavilhão

Leônidas Deane, $6^{\circ}$ andar, sala 607, Rio de Janeiro, RJ 21040-900, Brazil

Full list of author information is available at the end of the article
} permits use, sharing, adaptation, distribution and reproduction in any medium or format, as long as you give appropriate credit to the original author(s) and the source, provide a link to the Creative Commons licence, and indicate if changes were made. The images or other third party material in this article are included in the article's Creative Commons licence, unless indicated otherwise in a credit line to the material. If material is not included in the article's Creative Commons licence and your intended use is not permitted by statutory regulation or exceeds the permitted use, you will need to obtain permission directly from the copyright holder. To view a copy of this licence, visit http://creativecommons.org/licenses/by/4.0/. The Creative Commons Public Domain Dedication waiver (http://creativeco mmons.org/publicdomain/zero/1.0/) applies to the data made available in this article, unless otherwise stated in a credit line to the data. 
Keywords: Surveillance, Hospital infection, Antimicrobial resistance, Klebsiella pneumoniae, Time series, Geographic information system, Spatial-temporal statistics

\section{Background}

The emergence and spread of antimicrobial resistance (AMR) in recent decades have challenged hospitals, especially by Gram-negative bacteria with multipledrug resistance (MDR) mechanisms, as the development and access to the therapeutic options for treating infections caused by these agents are still limited. In addition, bacterial cross-transmission between patients and transfer of AMR genes between bacteria are increasingly more well recognised in hospitals [1-3]. Consequently, the incidence of healthcare-acquired MDR Gram-negative bacteria has increased dramatically over the last decades making AMR monitoring and containment critical.

Currently, Klebsiella pneumoniae is a good example of a hospital-acquired pathogen that often causes colonisation and infection, with high morbidity and mortality rates and costs [4-7]. The global expansion of hypervirulent and MDR clones of K. pneumoniae has been increasingly reported, especially of carbapenem-resistant strains [5, 8-14]. In the study hospital, we experienced an evolving epidemiology among $K$. pneumoniae with clonal PDR/XDR KPC-2-producing ST437 strains causing intractable infections between 2014 and 2015 [7]. These events led us to investigate a new approach to monitor AMR, since effective control requires a detailed understanding of how the dynamics of the agent's circulation in the hospital occur.

Geographic information system (GIS) is a well-known system that aims to visualise, explore and model in a fast, direct, simple and interactive way, thus allowing mapping of events and enabling the analysis of spatial information in different degrees [15-17]. Although GIS is widely used in health [15-17], it has not been well explored for surveillance of infectious agents throughout hospitals [18].

Investigating the circulation of MDR bacteria, specifically using members of $K$. pneumoniae complex as a model, with spatiotemporal epidemiological techniques within a hospital unit, is a method that may identify critical areas and outbreaks, helping to improve surveillance and control of healthcare-associated infection and may prevent dissemination of AMR microorganisms. We hypothesised that this novel methodology would have sufficient accuracy to be performed indoors to facilitate the monitoring of any infectious agents and AMR profiles interactively. Therefore, our main goal was to demonstrate the feasibility and gains of conducting surveillance of a target infectious agent by using routine monitoring data to detect clusters through robust spatial epidemiological tools in a hospital.

\section{Methods \\ Study design, setting and period}

This retrospective study was carried out in a 450-bed federal tertiary hospital located in Rio de Janeiro. This research has been approved by the institutional review board with an informed consent waiver. We followed ORION statements in this study report [19].

All isolates of $K$. pneumoniae complex were investigated from the database of the hospital's microbiology laboratory, without repetition (only the first isolate was used whenever more than one isolate of $K$. pneumoniae complex was detected in the same biological sample collected on the same day), recovered from clinical and surveillance samples from patients hospitalised in intensive (ICU) and nonintensive care wards in the years of 2014 to 2016. We did not perform any exclusion criteria in the data collection phase, but only in the analysis phase of the study, therefore, only the patient's first isolate with the specific phenotype was used to estimate incidence density rates and identify carrier status.

\section{Hospital physical structure and basic map construction}

A basic longitudinal map with a scale of the hospital's physical structure was developed in AutoCAD (DWG archives) and converted to QGis software (version 2.18, Open Source Geospatial Foundation), providing the construction of the first version of the hospital's GIS. All intensive $(n=6)$ and nonintensive $(n=73)$ care wards located on the 11th and 5th floors of the main and annex buildings, respectively, were mapped. Additional file 1: Table S1 shows the number of floors, units and beds of each building and Additional file 1: Fig. S1 shows their features mapped in QGis.

\section{Microbiological samples, bacterial identification and susceptibility testing}

Clinical samples for microbiological exams were routinely collected by primary physicians as part of the investigation of infectious processes, guided by microbiological protocol implemented throughout the institution by the Hospital Infection Control Committee (HICC), during the study years. Rectal swabs for surveillance were collected weekly or every 15 days at all ICUs and 
systematically performed in nonintensive hospital areas according to the institutional HICC and microbiology laboratory protocol (Additional file 1: Table S2). Identification and antibiotic susceptibility testing of recovered strains were performed by conventional automated Vitek-2 system (BioMérieux, Marcy l'Etoile, France), including those from swabs. Etest and disk diffusion (Oxoid, Hampshire, UK) methods were used whenever indicated by the updated recommendation of the Clinical and Laboratory Standards Institute and European Committee on Antimicrobial Susceptibility Testing [20, 21]. Additional file 1: Table S3 shows the tested antibiotics. Screening for carbapenemase production was established by phenotypic tests with phenylboronic acid, EDTA and cloxacillin in a nonsystematic way by using carbapenemase inhibition test (CIT), as described elsewhere [22-24]. We classified the resistant profile of strains as non-MDR, MDR, possible extensively-drug (XDR) or pandrug (PDR) resistant, according to Magiorakos et al. [25]. Carbapenem-resistant $K$. pneumoniae (CRKp) complex isolates randomly preserved during this period and sent to Hospital Infection Research Laboratory of FIOCRUZ were also investigated to confirm microbial identification through classical methods [26] and for the search of carbapenemase genes $\left(b l a_{\mathrm{KPC}-2}, b l a_{\mathrm{NDM}-1}\right.$ and $\left.b l a_{\text {OXA-48-like }}\right)$ using in-house multiplex polymerase chain reaction.

\section{Patient data}

All inpatients with the detection of $K$. pneumoniae complex in any biological sample had the hospital records investigated for date, bed, ward and clinic of admission, date of discharge and transfer between beds. Patients were considered to be colonised or infected with carbapenem-resistant strains after the first detection of isolates with this resistance profile, for the remaining hospitalisation period and during readmissions.

\section{Georeferencing of bacteria and patients}

The occurrences of members of $K$. pneumoniae complex with the susceptibility profile classified as above and also those detected as carbapenem resistant were entered manually into the QGis software and plotted on the map and georeferenced according to hospital ward and detection date. Likewise, patients harbouring CRKp complex were georeferenced for the duration of hospitalisation. In other words, we georeferenced different bacteria phenotypes and patients carrying a specific phenotype. When georeferenced bacteria phenotypes we consider all agents, with the exclusion criteria mentioned above. While when georeferenced patients carrying a specific phenotype, we considered only the first isolate with the specific phenotype (CRKp complex) by the period of hospitalisation. Thus, the circulation of patients carrying CRKp complex was investigated in space and time.

\section{Statistical analysis}

A descriptive analysis was performed by using $\mathrm{R}$ statistical package (R Core Team, 2019) and a spatial statistical analysis was performed by using SaTScan program [27]. In all analysis $p$ value $\leq 0.05$ was considered significant for both sides of the curve.

\section{General statistical analysis}

Exploratory data analyses were performed in the study. We used non-parametric Mann-Whitney and KruskalWallis tests for comparisons between groups, taking into account the total number of isolates and their susceptibility profiles, per month of detection or for the period of hospitalisation. Tests for equal proportions between groups were also used. We were not able to construct denominators (total patient-days) per ward of admission, but we used this information from the entire institution to estimate the incidence density of $K$. pneumoniae complex phenotypes during the study period. We estimate the monthly incidence density of target bacterial phenotype, considering only the first isolate of the patient with the respective phenotype per month, divided by the monthly total of patient-days normalised by 1000 . In time series analysis, we used the approximate Cox-Stuart trend test, we performed seasonal and trend decomposition based on Loess (STL) and we examined anomalies [28].

\section{Spatial statistical analysis}

Spatial statistical analyses were performed in order to detect clusters of patients harbouring CRKp complex through the SaTScan program (available in www.satscan. org). Two sets of data analysis were done. One of them aimed to verify the distribution and spatial pattern in the occurrence of $K$. pneumoniae complex isolates with the specific phenotype (non-MDR, MDR, possible-XDR or -PDR and CRKp) recovered from patients hospitalised in the study period, regardless of whether clinical or surveillance material, and according to the date, month and year in which the isolate was detected. Another set of data analysis was based on patients with a specific phenotype (CRKp complex) counted monthly from the day of the first detection to the date of hospital discharge or death. The X (horizontal distance) and $\mathrm{Z}$ (floor height) coordinates refer to lateral and height distances (between floors) amidst the centroids of the wards. The neighbourhood (proximity matrix) was created based on the Euclidean distance [29], i.e., the horizontal and vertical distance in meters between pairs of wards, assuming that nearby wards can be contaminated by the use of common equipment, the circulation of health professionals and 
visitors. The transfer of clustered patients between wards was investigated using a flow map connecting the origin and destination wards using arrows, indicating colonisation or infection by CRKp complex based on microbiological results routinely collected.

As no population-at-risk data were analysed by wards, the expected number of positive samples for each ward was calculated, using only the total number of cases, considering the stability in the number of sample collections and hospitalisations per month. In other words, the proportion of all observed cases that occurred in each ward by the total number of cases expected during the month. The space-time permutation model was chosen in this case since it dismisses denominators since the absolute number of cases are compared [27].

The spatial scan statistic using a space-time permutation model was performed by overlapping circles, in which their domains represented the two-dimensional ( $\mathrm{X}$ and Z) space of the hospital, and a third dimension represented time (month) to define the scan window. Thus, the number of monthly cases observed was counted and compared in and out of the circle, with the expected value being the average number of cases during the overall study period. The program marks the set of medical wards inside the circles with a statistically significant $(p<0.05$, assuming a Poisson statistical distribution) difference between the observed and expected number of cases. Circles represent clusters of cases, and can thus comprise a finite number of neighbour wards within a period of several months. Once these circles are identified, secondary indicators are calculated, such as the maximum likelihood ratio, statistical significance of clusters, and relative risks (RR). The circles' centre coordinate and circle radius (in meters) are also outputs from the program and were used to plot hot spots into the digital maps in GIS.

\section{Results}

\section{Georeferenced K. pneumoniae complex and resistant phenotypes}

Among the recovered information of a total of $759 \mathrm{~K}$. pneumoniae complex isolates from 564 patients, $40 \%$ $(n=303$ isolates) was retrieved from ICU and $60 \%$ $(n=456)$ from other noncritical areas (Additional file 1: Algorithm 1). Additional file 1: Table S1 shows the number of isolates per clinic in the main and the annex buildings and Additional file 1: Fig. S2 shows the mapped distribution of the isolates during the 3-year period. Two-thirds (509/759) of the isolates were detected from clinical samples such as urine $(46 \%, 232 / 509)$, blood $(29 \%, 146 / 509)$, and respiratory tract samples $(9 \%$, 48/509). The ratio of isolates per patient was 1.3:1, and $77 \%(432 / 564), 17 \%(94 / 564)$ and $6 \%(35 / 564)$ of patients had, respectively, 1, 2 and $\geq 3$ strains recovered from different samples during the study. Only $3 \%(19 / 564)$ of the patients had isolates detected in different samples from the same day. Different and progressively more resistant phenotypes were detected respectively in 36\% (47/129) and $23 \%(29 / 129)$ of our patients with two or more isolates. Fifty-nine percent (17/29) of the patients with progressively more resistant phenotypes had the isolates detected in different months. Surveillance rectal swabs accounted for $33 \%$ (250/759) of isolates, with $74 \%$ of those recovered from ICUs (186/250). Resistance to any carbapenems (investigated in the entire hospital) was found in $76 \%(189 / 250)$ of rectal swab isolates and $24 \%$ $(61 / 250)$ had carbapenem susceptible ESBL-positive phenotype (investigated mainly in paediatric wards).

In addition to the increase of $K$. pneumoniae complex detection between 2014 and 2016, corresponding to a similar proportion of less than $1 \%$ of the total number of microbiological exams performed in the hospital in $2014(0.7 \%, 212 / 32,560$; 95\% CI: $0.56-0.75 \%), 2015$ (0.8\%, 260/31, 364; 95\% CI: 0.73-0.94\%) and 2016 (0.9\%, 287/33, 290; 95\% CI: 0.77-0.97\%), a significant increase $(p<0.001)$ of possible XDR/PDR strains was identified from 2014-2016 and shown by this spatial methodology (Additional file 2: Fig. S3). This was also verified by the monthly incidence density, per 1000 patient-days, of patients with $K$. pneumoniae complex phenotypes investigated in this study (Additional file 1: Fig. S4). Almost all possible XDR/PDR strains $(99 \%, 164 / 166)$ displayed resistance to carbapenems.

\section{CRKp complex and time series analysis}

Among CRKp complex (35\%, 265/759), which corresponded to $56 \%(265 / 472)$ of the MDR strains recovered from 175 patients (1.5:1 isolates per patient ratio), in which $28 \%(n=49)$ and $17 \%(n=30)$ of the patients had two or more isolates detected, respectively, during the study period and at the same month. Only 7\% (18/265) of isolates were detected in the first $48 \mathrm{~h}$ of admission. Therefore, 93\% (247/265) of isolates were associated with hospitalisation. Resistance to meropenem was diagnosed in $99 \%(213 / 214)$ of tested isolates, with high-level resistance (minimum inhibitory concentration, MIC $\geq 16 \mu \mathrm{g} /$ $\mathrm{ml})$ in $88 \%(187 / 213)$. For imipenem tested isolates $61 \%$ $(107 / 175)$ had $\mathrm{MIC} \geq 16 \mu \mathrm{g} / \mathrm{ml}$ (Additional file 1: Fig. S5). One hundred percent of clinical tested CRKp complex strains $(\mathrm{n}=38)$ had a positive screening for the production of carbapenemase. $b l a_{\mathrm{KPC}-2}, b l a_{\mathrm{OXA}-48 \text {-like }}$ and $b l a_{\mathrm{NDM}-1}$ were detected respectively in $83 \%$ (71/86), $7 \%$ $(6 / 86)$ and 6\% (5/86) of preserved CRKp complex from rectal swabs $(n=50)$ and clinical samples $(n=36)$, confirming $91 \%$ (78/86) with this mechanism of resistance. 
In time-series analyses, regardless of biological material, whether clinical or surveillance, there was a significant increase $(p$ value $<0.001)$ in the occurrence of patients harbouring CRKp complex (Additional file 1: Fig. S6). This was confirmed by STL decomposition, which also showed a seasonal increment in the second half of each year (Additional file 1: Fig. S7), irrespective of clinical or surveillance material and without the interference of detected anomalies (Additional file 1: Fig. S8).

\section{Georeferenced CRKp complex isolates}

The increased in CRKp complex carriers is shown unequivocally and in a more specific way by the annual hospital GIS (Additional file 1: Fig. S9) with mapped occurrences by wards. In general, intensive- or nonintensive-care adult wards $(258 / 265,97 \%)$ had a significantly higher frequency of carbapenem-resistant strains (total number of CRKp complex isolates divided by the total number of K. pneumoniae complex detected, multiplied by 100) than paediatric wards of any kind $(7 / 265$, $3 \%)(p=0.02)$ (Additional file 1: Fig. S9). The occurrences in paediatrics were predominantly of surveillance swabs $(n=6)$ with only one blood sample from Paediatric ICU. Maternity had 1 rectal swab only. CRKp complex was more prevalent in medical wards than in surgical or clinical-surgical ones $(p \leq 0.001)$. The occurrence of patients harbouring CRKp complex was higher in ICU than in non-ICU $(p \leq 0.001)$. Floors with ICUs $(p \leq 0.001)$, and wards with multiple beds when compared to single rooms $(p \leq 0.001)$, had higher occurrences of CRKp complex. The adult ICU (\#100 on map) had a high and constant occurrence throughout the period, regardless of clinical or surveillance material. Investigation of space and time circulation of all patients carrying CRKp complex showed that although adult ICU was the most frequent site of first detection (Additional file 1: Fig. S10B), non-critical sectors also pressured this ICU with transfer of colonised/infected patients (Additional file 1: Fig. S10C).

\section{Space-time clusters of patients with CRKp complex infection/colonisation}

The first detected cluster of patients with CRKp complex occurred in wards located on the central and left side of the main building, during the entire second half of 2014 $(\mathrm{RR}=2.73, p=0.0016)$ (Fig. 1). This cluster was affecting 8 adult patients representing 13.1 patient-months (the total number of bed-months that the affected patients

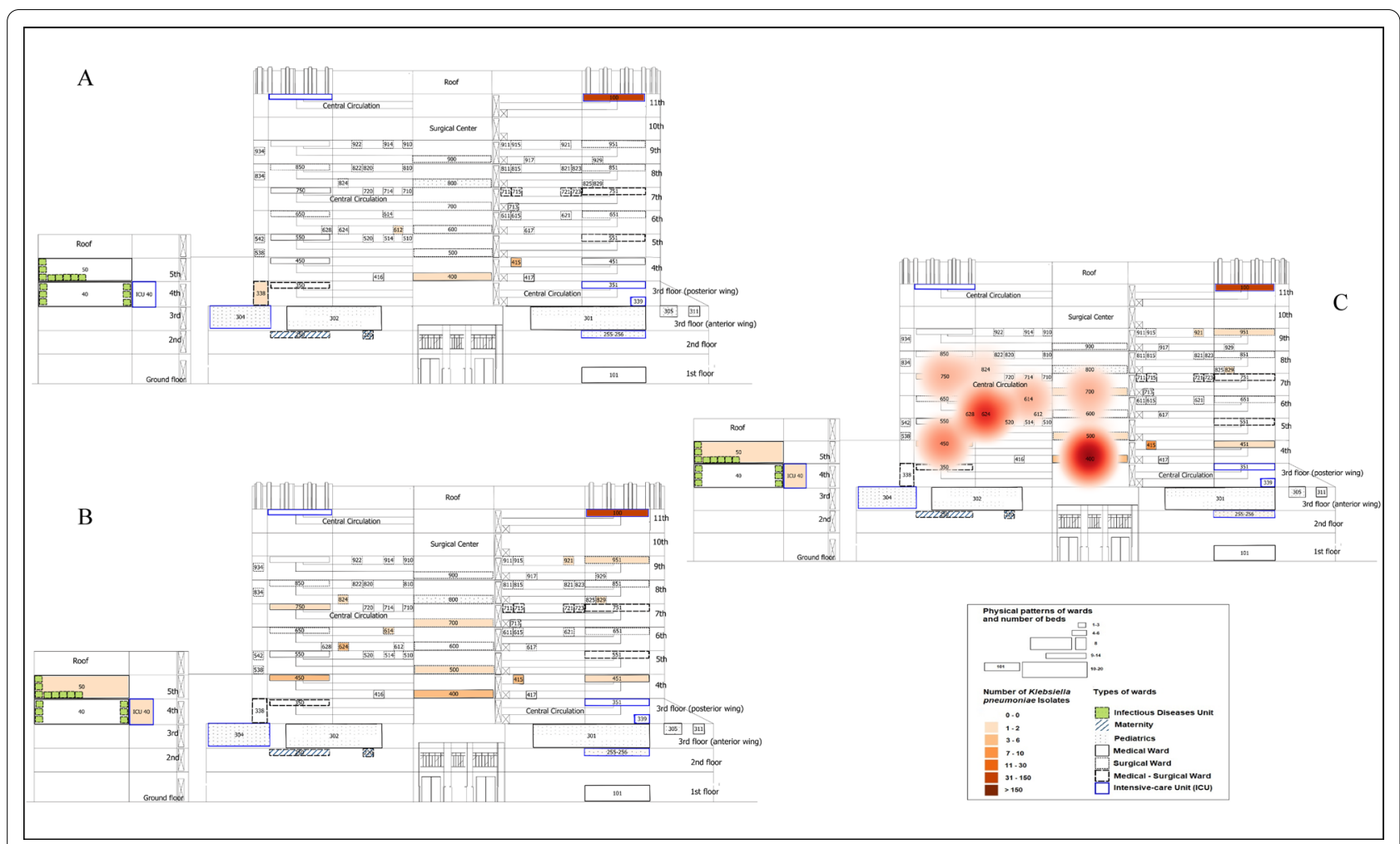

Fig. 1 Cluster of patients harbouring carbapenem-resistant Klebsiella pneumoniae complex, tertiary federal hospital. a Pre-cluster period, 1st semester 2014; b Cluster period, 2nd semester 2014; c Cluster represented in heat map layer in red tones, the higher the colours tone the higher the occurrence, 2nd semester 2014 (affecting the wards of numbers 400, 450, 500, 614, 624, 700, 750, 824), $p=0.0016$ 
contributed to the cluster) (Additional file 1: Fig. S11 and S12) or 394 patient-days (the total number of beddays that the affected patients contributed to the cluster) of colonisation in the cluster area (clinical, clinical-surgical or surgical wards located on the 4th to 8th floor). A second cluster occurred on the right side of the central building also on different floors (Fig. 2), extending from October 2015 to mid-2016 (9 months duration) $(\mathrm{RR}=1.91, p=0.004)$. This cluster affected 14 adults and 1 child representing 28.8 patient-months (Additional file 1: Fig. S11 and S12) or 865 patient-days of colonisation in the cluster area (coronary ICU, internal medicine, general duty and a paediatric ward). The epidemiological and microbiological characteristics of patients involved in the first and second cluster are shown in Additional file 1: Table S4. None of these clusters was perceived by the regular AMR surveillance and control program performed daily by the HICC (Additional file 1: Table S5), although $87 \%(20 / 23)$ of clustered isolates represented hospital-associated infection or colonisation.

Patient flow maps (Fig. 3) and Additional file 1: Fig. S12 show the epidemiological link between clustered patients and clearly demonstrated that the adult ICU (ward \#100) was involved in both clusters, but in the second cluster, the coronary ICU (ward \#351) was the hot spot affecting neighbouring wards. Only three strains (patients \#3, \#8 and \#13) of the second cluster had carbapenemase genes investigated and all were $\mathrm{KPC}-2$ producing and negative for NDM-1 and OXA-48 genes. These patients have never met physically during the hospitalisation period, although they were admitted to the same wards (Fig. 3, Additional file 1: Fig. S12). Seven out of nine patients (78\%) in the first cluster and 27\% (4/15) in the second cluster had an opportunity for bacteria transmission among them. Figure 3 also shows the patient's status of colonisation/infection by CRKp complex during transfers between intensive and non-intensive wards.

\section{Discussion}

The use of in-hospital GIS associated with the spatial statistics for endemic level monitoring and cluster detection of patients harbouring AMR bacteria is feasible. As far as we know, this is the first study to develop a surveillance methodology using GIS and spatial statistics to investigate and monitor target microorganisms causing infection/colonisation in patients from all sectors of the hospital for 3 consecutive years.

In spite of the literature recommending the use of GIS $[18,30]$, and spatial statistics for data analysis in hospitals and health units for almost two decades [17, 31], none of

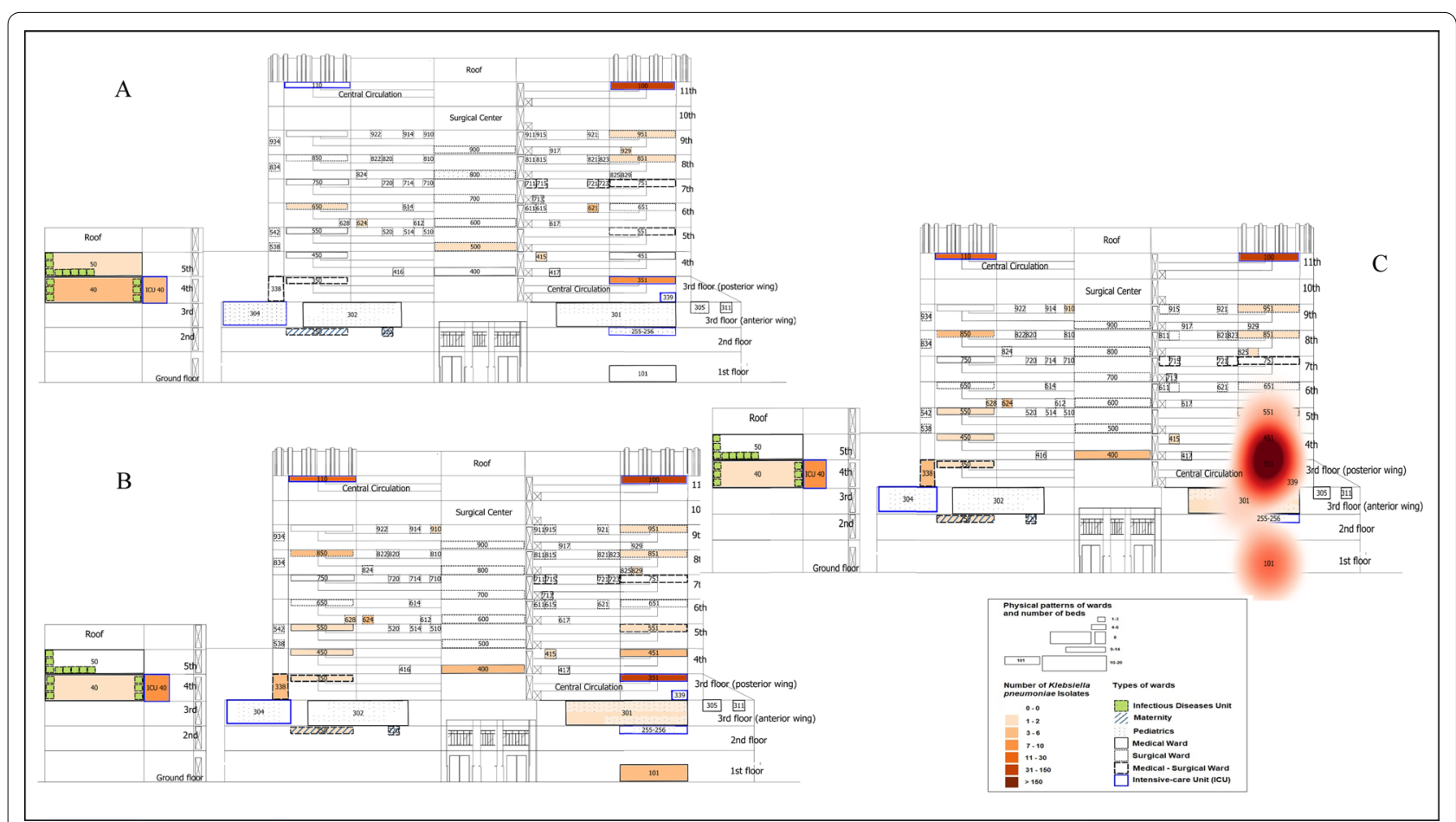

Fig. 2 Cluster of patients harbouring carbapenem-resistant Klebsiella pneumoniae complex, tertiary federal hospital. a Pre-cluster period, January to September 2015; b Cluster period, 4th quarter 2015 to 1st semester 2016; c Cluster represented in heatmap layer in red tones, the higher the colours tone, the higher the occurrence, 4th quarter of 2015 and 1st semester of 2016 (affecting the wards of numbers 101, 301, 351, 451, 551), $p=0.004$ 


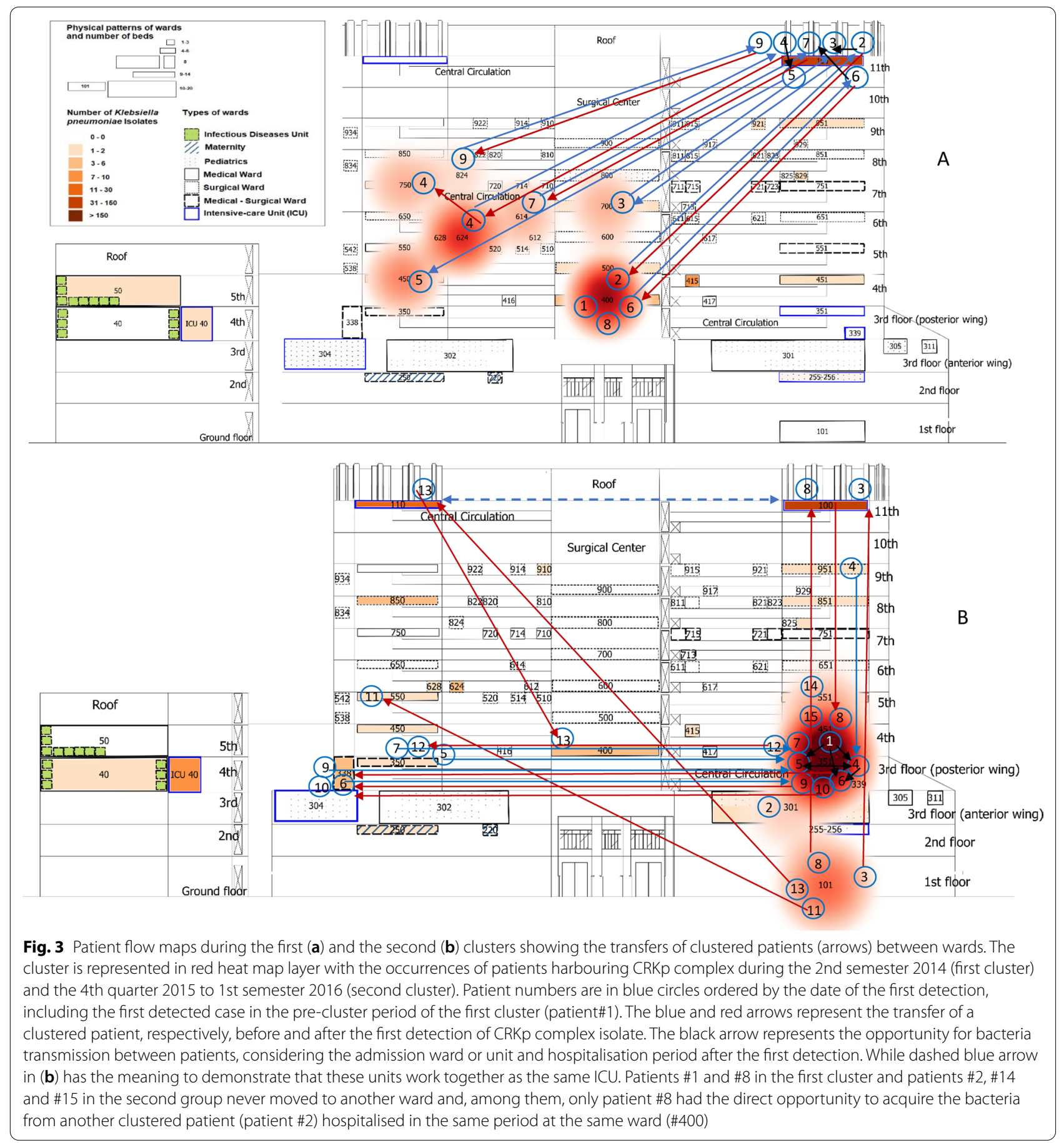

the studies used both tools for AMR surveillance and the number of in-hospital studies remains very incipient [17, 18, 30, 31]. Several sites and applications nowadays use GIS to gather and monitor infectious disease data worldwide (https://www.healthmap.org/en/; https://omict ools.com/biocaster-tool; https://www.istm.org/geose ntinel). These are bio-surveillance systems that capture, organise and analyse public health information that can be accessed by anyone on the internet, but none of them has applicability to in-hospital epidemiology. A new version of WHONET 2019 (http://www.whonet.org/index. html) uses Martin Kulldorf's trademark SaTScan ${ }^{\mathrm{TM}}$ to detect space-time clusters, including MDR bacteria in hospitals. The site reports the same statistical method 
used in our study in a 5-year project, but with no mention of in-hospital GIS.

The occurrence of MDR Gram-negative microorganisms in hospitals increases geometrically and surveillance manuals are regularly renewed [32-35], while methodologies for mapping events and detecting clusters in hospitals need to progress at the same pace [13]. The spread of $K$. pneumoniae producing KPC carbapenemases has become an unparalleled public health crisis [7-11, 14]. In the studied hospital, the impact of evolving epidemiology with a global dimension was not different with an important increase in the resistance profiles of $K$. pneumoniae complex over the years [7].

Clusters of patients with CRKp complex in different hospital areas and floors, where most workflows are generally differentiated, would probably be overlooked by the surveillance methodologies currently used to control hospital-acquired infections. In the literature, we found no publications mentioning similar bacterial outbreak affecting adult and paediatric units located on different hospital floors. This partly explains why these were not noticed by the hospital surveillance system that used methodology without GIS and spatial statistics. Moreover, clusters affecting non-critical areas with lower frequencies were likely disregarded due to the higher occurrence in ICUs, where the higher-level resistance profile (concomitant resistance to polymyxin) probably attracted more attention from our HICC [7]. The use of both technologies offered the advantage of monitoring a large number of data and different resistance patterns in hospital clinical areas with different endemic levels.

In this study, Additional file 1: Fig. S11 and S12 represent the traditional methodology for mapping occurrences without GIS and spatial statistics, while Figs. 1, 2 and 3 and Additional file 1: Figures S2, S9, S10 and Additional file 2: Figure S3 represent the new method for mapping the occurrences. The visual aspect of the new method contributes to understanding the complexity of in-hospital surveillance, whilst the detection of spatialtemporal clusters affecting diverse clinics on dissimilar floors, during the period of months, is likely only possible by using the space-time clustering method.

The agglomeration in time and space and flow of patients harbouring CRKp complex indicates the need to investigate the clonal aspects of isolates and the sources of dissemination. Therefore, molecular genetics of the microorganism is a necessary step for precise discrimination of $K$. pneumoniae from related phylogroups and genotyping [36]. There are several potential sources of transmission of $K$. pneumoniae complex that needs to be further explored in the hospital [5]. Radiology, operating rooms, support services such as hospital hygiene, laboratory, nutrition and even consulting professionals serving different areas of adults and paediatrics could serve as vehicles or sources of transmission in different floors and units. Silent colonisation is useful to explain some of our results $[13,37]$. This becomes apparent when the resistant organism was detected in other clustered patients who never met physically but were hospitalised in the same wards.

The clusters last a few months in diverse neighbouring wards, indicating a continuous and widespread circulation of resistant bacteria between intensive and nonintensive care areas. The possibility of infection spread from critical wards to nearby health units throughout months is a clue to preventive measures [13]. Although real-time spatial monitoring of AMR can provide early warnings for infection control from its origin, potential carriers (equipment, health professionals, etc.) and transmission routes, bacterial genotyping is required for investigating in-hospital bacterial transmission [13]. The lack of genetic analysis of isolates is an important limitation in this study, especially for confirming outbreaks.

The addition of the use of hospital GIS and spatial statistics to other surveillance measures already used in hospitals, such as previous antimicrobial consumption, can be an important milestone for renewing the monitoring and control of diseases that kill thousands worldwide each year. The management of several infections and activities that take place within a hospital can benefit from this GIS methodology to ensure the safety of patients and healthcare professionals. Georeferencing patients, staff, visitors, or even hand hygiene locations and hours between or in contact with inpatients, among other factors that involve this issue, would help to understand and control the main sources and routes of transmission of microorganisms in hospitals [18, 30]. Further studies of this nature would improve the knowledge about the dynamics of microorganisms and thus contribute to the construction or remodelling in order to better meet workflows and prevent the circulation of infectious agents and the risk of transmission. This interactive and visual approach, specifically demonstrating which room, ward, corridor, floor, not just the clinic, and whenever events begin, would be performed prospectively in realtime and in $3 \mathrm{D}$ to proactively impact the health professionals' adherence to infection prevention and control in the future.

Although challenging, the methodologies using georeferencing software are on the internet. QGis software is free to download (https://qgis.org/en/site/forusers/downl oad.html). Hospitals often have architects who support the construction and renovation of physical facilities. The application of spatial statistics would require skilled professionals, but more and more technologies that enable 
interactive learning or the use of this tool are becoming available on the internet (http://www.whonet.org), and hospitals could incorporate specialised personnel. Additionally, integrated real-time GIS components have been used for real-time surveillance [38]. Similarly, the microbiology laboratory system can be integrated with QGis and $\mathrm{R}$, since both statistical packages allow for many spatial analyses in an automated mode [39].

Since this is a retrospective study, several limitations are expected. First, our intention was to demonstrate a new approach to detect clusters, which can be simply defined as an aggregation of cases grouped in place and time [40]. We did not aim to investigate outbreaks [40], because of the retrospective nature of the study. We cannot provide the analysis of infectious rates because we worked only with the hospital's microbiology laboratory database. We investigated real-life data of K. pneumoniae complex isolates recovered from all clinical and surveillance material and excluded only isolates from the same biological sample collected on the same day. We did this at the beginning to make sure we would not introduce any bias into the study, since all laboratory results are important for spatial and temporal monitoring of agents' AMR phenotypes.

Considerable variation in AMR data analysis still present and some of recommendations were made for reporting [41], but not for real-life surveillance as our purpose. Since we monitored different phenotypes of $K$. pneumoniae, we cannot include the first isolate from each patient only. This is especially important because different phenotypes can circulate concomitantly in the same patient, in blood and rectal swabs for example. In addition, the emergence of resistance during hospitalization in a given species in the same patient can only be suspected by following all isolates and phenotypes [7]. We chose to use in this study the same and minimum data that the HICC works initially and daily to monitor bacterial agents. Additional file 1: Figure S2 and Additional file 2: Figure S3 represent georeferenced bacteria phenotypes considering all agents included, so one limitation of this approach is that we cannot counted each isolation as a different process of infection or colonization as a prior convention [42, 43]. While Figs. 1, 2 and 3 and Additional file 1: Figures S9 and S10 represent georeferenced patients considering the first isolate with the specific phenotype by the period of hospitalisation. Nevertheless, we probably investigated a smaller tip of the iceberg; sample collection was performed during the routine investigation of infectious processes in hospitalised patients, and carbapenem-resistant Enterobacteriaceae surveillance performed differently in critical and non-critical units. Thus, the results do not represent the actual occurrence.
The seasonal increase in CRKp complex carriers detected in time series analysis also deserves further investigation and may pose an additional challenge with regard to control outbreaks [11]. A multivariate analysis considering other variables such as length of hospital stay, previous use of antimicrobials and age would be important to better estimate rates. In addition, our data point to a statistical analysis of the longitudinal study considering a nonlinear multivariate regression, based on recent literature [44], with different levels of correlation among the same or different patients, in the same or in different wards.

Although colonised/infected patients are the main reservoirs and sources of bacterial circulation, healthcare workers also participate in the dynamics of infectious agents in hospitals [34]. The transmission routes and contact network between clusters can also be investigated by space-time scan statistics [45]. The proximity matrix can be improved in the future, using data on the flow of patients, health professionals and medical materials. The 1-month timescale was designed to mimic what is normally reported in-hospital surveillance, but a more refined scale will be necessary in real life [45].

Using the space-time permutation model without the use of denominators, such as total patient-days or total admissions, considering the stability in the number of samples collected and hospitalisations (data not shown), may facilitate and improve resistance surveillance locally in hospitals, especially in low-income countries, as the construction of denominators by infirmaries requires greater robustness of information, which is not always feasible. Although this is a limitation to compare rates between institutions, it is also a strong point, as it simplifies the monitoring of AMR, facilitating early detection in a hospital. Space-time permutation scanning statistic is a methodology designed for the early detection of events that uses only case numbers, with no need for population-at-risk data [27, 46]. But spatial statistics can be used with denominators improving comparability among institutions.

Nevertheless, we consider that none of these limitations interfered with our purpose to demonstrate a different approach for cluster detection with the substantial amount of data that HICC usually works with. The GIS methodology was designed to attend the real-life monitoring and can be applied using different AMR monitoring criteria. Our observation is that the amount of microbiological data, with the variety of target AMR phenotypes in hospitals, requires automated methods using spatial statistics for cluster detection. New and traditional methodologies for hospital surveillance are likely complementary, but more studies are needed to compare 
the benefit of each approach, the reliability of the mathematical model chosen and how it would do better for surveillance of AMR or any infectious agent in hospital. Finally, but not least, the rates found, although underestimated, are useful to demonstrate the importance of the theme in the hospital.

\section{Conclusions}

The spatial methodology can be applied in hospital; it was useful for detecting clusters and has the potential to facilitate the early recognition of hospital outbreaks, even in different wards and floors. Any healthcare-associated infection could likely benefit from this methodology, including non-border resistant bacteria. Spatial statistical analysis of georeferenced microorganism in hospitals may become a new instrument for health care institutions in the fight against target infectious agents and AMR.

\begin{abstract}
Abbreviations
AMR: Antimicrobial resistance; CRKp: Carbapenem-resistant K. pneumonia; GIS: Geographic Information System; HICC: Hospital Infection Control Committee; ICU: Intensive care units; KPC-2: K. pneumoniae Carbapenemase 2; MIC: Minimum Inhibitory Concentration; MDR: Multidrug resistant; NDM-1: New Delhi metallo-beta-lactamase 1; OXA-48: Oxacillinase-48-like carbapenemases; ORION: Outbreak Reports and Intervention Studies of Nosocomial infection; PDR: Pandrug resistant; QGis: Quantum GIS; RR: Risk relative; STL: Seasonal and Trend decomposition based on Loess; XDR: Extensively drug resistant.
\end{abstract}

\section{Supplementary Information}

The online version contains supplementary material available at https://doi. org/10.1186/s13756-021-00944-5.

Additional file 1: Table S1. Distribution of wards and beds, and the number of Klebsiella pneumoniae complex isolates per type of ward, unit and floor in the Main and Annex buildings. Fig. S1. Thematic hospital map in QGis format. Table S2. Rectal swab protocol for surveillance of antimicrobial resistant Enterobacteriaceae. Table S3. Categories and antimicrobial agents used for susceptibility testing on K. pneumoniae complex. Algorithm 1. K. pneumoniae complex isolates included and excluded according to the hospital sectors of detection and the reason for exclusion. Fig. S2. Mapped distribution of K. pneumoniae complex isolates. Fig. S4. Monthly incidence density of patients infected/colonised by K. pneumoniae complex per 1000 patient-days according to respective phenotypes. Fig. S5. Minimal inhibitory concentration (MIC) of meropenem and imipenem among carbapenem-resistant $K$. pneumoniae (CRKp) complex recovered from inpatients. Fig. S6. Time series analysis of patients harbouring CRKp complex adjusted by number of microbiological exams performed monthly. Fig. S7. Seasonal Trend decomposition using LOESS (STL) - Time series analysis of patients harbouring CRKp complex. Fig. S8. Seasonal Trend decomposition for data anomaly taking into the account time series data of patients harbouring CRKp complex. Fig. S9. Pattern of annual distribution of patients harbouring CRKp complex. Fig. S10. Space and time circulation of all patients carrying CRKp complex by ward of admission; before, at the time and after the detection of CRKp complex colonisation or infection. Fig. S11. Number of patients infected or colonised by CRKp complex by clustered wards and month of hospitalization, during the first and the second pre-cluster, cluster and post-cluster period. Table S4. Epidemiological and microbiological characteristics and outcome of patients involved in the first and second cluster. Fig. S12.
Epidemiological link between patients colonised or infected by CRKp complex during the first cluster and the second cluster.

Additional file 2: Fig S3. Thematic hospital maps of annual detection of $K$. pneumoniae complex according to the antimicrobial susceptibility profiles and regardless of clinical or surveillance samples.

\section{Acknowledgements}

Hospital Infection Research Laboratory (IOC/FIOCRUZ) for microbiological confirmation and for the search of carbapenemase genes in preserved CRKp isolates. Voluntary program of Oswaldo Cruz Institute, FIOCRUZ for the voluntary work of some Nucleus of Hospital Research study collaborators (MCS, MMC, YRM). The research leading to these results is supported by the Technical Cooperation Agreement (Number 51/2017) between FIOCRUZ and HFSE to develop research.

Nucleus of Hospital Research (NPH) study collaborators: Vitoria Pinson Ruggi Dutra, Maxuel Cassiano da Silva, João Pedro Silva Tonhá, Luciana Sênos de Mello, Murillo Marçal Castro, Yann Rodrigues Mathuiy and Amanda Aparecida da Silva Machado. Email address of study collaborators: vitoriapinsonrd@ gmail.com, maxcsva@gmail.com, joaopedrotonha@gmail.com, senos.luciana@ gmail.com, murillocastro.med@gmail.com, yannrm.unirio@gmail.com, amandacidamachado@gmail.com.

Preliminary results from this study were presented at the IV Simpósio e $5^{\circ}$ Workshop em Pesquisa, Desenvolvimento e Inovação em Doenças Bacterianas e Fúngicas, in November 23rd, 2018, in FIOCRUZ, Rio de Janeiro, Brazil.

\section{Authors' contributions}

MZRG, CB and WST were involved in the conception and design of the study. MZRG obtained scholarships. FAS and CNC built the basic map. PPS collected the data. CASR, LPS, EML and MHBP contributed to data collection. MZOA worked in database design and management features. PPS and MZRG involved in the preparation of thematic maps. MZRG, CB, WST and PPS analysed and interpreted the data. MZRG and PPS wrote the manuscript. All authors read and approved the final manuscript.

\section{Funding}

Coordination for the Improvement of Higher Education Personnel (CAPES) for providing scholarships for Priscila P. da Silva in the Post-graduation Course in Tropical Medicine, Oswaldo Cruz Institute, FIOCRUZ. Research Support Foundation of the State of Rio de Janeiro (FAPERJ) and National Council for Scientific and Technological Development (CNPq) for providing scholarships for scientific initiation for undergraduate medical students (VPRD, JPST, LSM, AASM). CNPq financial support number 438015/2018-5.

\section{Availability of data and materials}

The datasets used and/or analysed during the current study are available from the corresponding author on reasonable request.

\section{Declarations}

\section{Ethics approval and consent to participate}

This study was approved by FIOCRUZ and HFSE Ethics Committees (CAAE: 60493516.6.0000.5248 and CAAE 60493516.6.3001.5252, respectively).

\section{Consent for publication}

Not applicable.

\section{Competing interests}

The authors declare that they have no competing interests.

\section{Author details}

'Laboratório de Genética Molecular de Microrganismos, Instituto Oswaldo Cruz - Fundação Oswaldo Cruz, Avenida Brasil, 4365, Pavilhão Leônidas Deane, $6^{\circ}$ andar, sala 607, Rio de Janeiro, RJ 21040-900, Brazil. ${ }^{2}$ Department of Engineering, Hospital Federal Dos Servidores Do Estado (HFSE), Rio de Janeiro, RJ, Brazil. ${ }^{3}$ Laboratory of Microbiology, HFSE, Rio de Janeiro, RJ, Brazil. ${ }^{4}$ Hospital Infection Control Committee, HFSE, Rio de Janeiro, RJ, Brazil. ${ }^{5}$ Admitting Office, HFSE, Rio de Janeiro, RJ, Brazil. ${ }^{6}$ Department of Mathematics, The Federal Rural University of Rio de Janeiro, Rio de Janeiro, RJ, Brazil. ${ }^{7}$ Institute of Scientific 
and Technological Communication and Information in Health, FIOCRUZ, Rio de Janeiro, RJ, Brazil. ${ }^{8}$ Present Address: Rio de Janeiro State University, Rio de Janeiro, Brazil. ${ }^{9}$ Present Address: Evandro Chagas National Institute of Infectious Diseases, FIOCRUZ, Rio de Janeiro, Brazil.

\section{Received: 16 November 2020 Accepted: 26 April 2021} Published online: 16 June 2021

\section{References}

1. Livermore DM. Fourteen years in resistance. Int J Antimicrob Agents. 2012;39(4):283-94. https://doi.org/10.1016/j.ijantimicag.2011.12.012.

2. Halwani M, Solaymani-Dodaran M, Grundmann H, Coupland C, Slack R. Cross-transmission of nosocomial pathogens in an adult intensive care unit: incidence and risk factors. J Hosp Infect. 2006;63(1):39-46. https:// doi.org/10.1016/j.jhin.2005.10.012.

3. Peterson E, Kaur P. Antibiotic resistance mechanisms in bacteria: relationships between resistance determinants of antibiotic producers, environmental bacteria, and clinical pathogens. Front Microbiol. 2018:9:2928. https://doi.org/10.3389/fmicb.2018.02928.

4. Guh AY, Bulens SN, Mu Y, Jacob JT, Reno J, Scott J, et al. Epidemiology of carbapenem-resistant Enterobacteriaceae in 7 US communities, 2012-2013. JAMA. 2015;314(14):1479-87. https://doi.org/10.1001/jama. 2015.12480.

5. Martin RM, Cao J, Brisse S, Passet V, Wu W, Zhao L, et al. Molecular epidemiology of colonizing and infecting isolates of Klebsiella pneumoniae. mSphere. 2016;1(5):12. https://doi.org/10.1128/mSphere.00261-16.

6. Paczosa MK, Mecsas J. Klebsiella pneumoniae: going on the offense with a strong defense. Microbiol Mol Biol Rev. 2016;80(3):629-61. https://doi. org/10.1128/MMBR.00078-15.

7. Gomes MZR, Lima EM, Pereira PS, Aires CAM, Menicalli MJS, Souza CMR, et al. Clonal pan or extensively drug-resistant KPC-2-producing ST437 Klebsiella pneumoniae causing untreatable infections evidenced by in vitro synergy testing. Open Forum Infect Dis. 2016. https://doi.org/10. 1093/ofid/ofw172.1558.

8. Munoz-Price LS, Poirel L, Bonomo RA, Schwaber MJ, Daikos GL, Cormican $\mathrm{M}$, et al. Clinical epidemiology of the global expansion of Klebsiella pneumoniae carbapenemases. Lancet Infect Dis. 2013;13(9):785-96. https:// doi.org/10.1016/S1473-3099(13)70190-7.

9. Moradigaravand D, Martin V, Peacock SJ, Parkhill J. Evolution and epidemiology of multidrug-resistant Klebsiella pneumoniae in the United Kingdom and Ireland. MBio. 2017. https://doi.org/10.1128/mBio.01976-16.

10. Gu D, Dong N, Zheng Z, Lin D, Huang M, Wang L, et al. A fatal outbreak of ST11 carbapenem-resistant hypervirulent Klebsiella pneumoniae in a Chinese hospital: a molecular epidemiological study. Lancet Infect Dis. 2018;18(1):37-46. https://doi.org/10.1128/mBio.01976-16.

11. Roux J, Nekkab N, Colomb-Cotinat M, Astagneau P, Crepey P. Time-series modelling for the quantification of seasonality and forecasting antibioticresistant episodes: application to carbapenemase-producing Enterobacteriaceae episodes in France over 2010-20. J Antimicrob Chemother. 2021;76(1):226-32. https://doi.org/10.1093/jac/dkaa388.

12. Zhu J, Li Q, Li X, Kang J, Song Y, Song J, et al. Successful control of the first carbapenem-resistant Klebsiella pneumoniae outbreak in a Chinese hospital 2017-2019. Antimicrob Resist Infect Control. 2020;9(1):91. https://doi. org/10.1186/s13756-020-00757-y.

13. Snitkin ES, Zelazny AM, Thomas PJ, Stock F, Group NCSP, Henderson DK, et al. Tracking a hospital outbreak of carbapenem-resistant Klebsiella pneumoniae with whole-genome sequencing. Sci Transl Med. 2012;4(148):148ra16. https://doi.org/10.1126/scitranslmed.3004129.

14. Tzouvelekis LS, Markogiannakis A, Psichogiou M, Tassios PT, Daikos GL. Carbapenemases in Klebsiella pneumoniae and other Enterobacteriaceae: an evolving crisis of global dimensions. Clin Microbiol Rev. 2012;25(4):682-707. https://doi.org/10.1128/CMR.05035-11.

15. Tassinari WS, Pellegrini DC, Sa CB, Reis RB, Ko Al, Carvalho MS. Detection and modelling of case clusters for urban leptospirosis. Trop Med Int Health. 2008;13(4):503-12. https://doi.org/10.1111/j.1365-3156.2008. 02028.x.

16. Barcellos C, Pustai AK, Weber MA, Brito MR. Identification of places with potential transmission of dengue fever in Porto Alegre using geographical information systems. Rev Soc Bras Med Trop. 2005;38(3):246-50. https://doi.org/10.1590/s0037-86822005000300008.

17. Davis GS, Sevdalis N, Drumright LN. Spatial and temporal analyses to investigate infectious disease transmission within healthcare settings. J Hosp Infect. 2014;86(4):227-43. https://doi.org/10.1016/j.jhin.2014.01.010.

18. Kho A, Johnston K, Wilson J, Wilson SJ. Implementing an animated geographic information system to investigate factors associated with nosocomial infections: a novel approach. Am J Infect Control. 2006;34(9):57882. https://doi.org/10.1016/j.ajic.2006.02.007.

19. Stone SP, Cooper BS, Kibbler CC, Cookson BD, Roberts JA, Medley GF, et al. The ORION statement: guidelines for transparent reporting of outbreak reports and intervention studies of nosocomial infection. Lancet Infect Dis. 2007;7(4):282-8. https://doi.org/10.1016/S1473-3099(07)70082-8.

20. CLSI. Clinical laboratory Standards Institute. Twentieteh fifth informational supplement. CLSI document M100-S25. 2018. http://www.facm.ucl.ac.be/ intranet/CLSI/CLSI-2015-M100-S25-original.pdf. Accessed 16 June 2018.

21. EUCAST. European Committee on Antimicrobial Susceptibility Testing Breakpoint tables for interpretation of MICs and zone diameters. Version 8.1, valid from 2018-05-15. 2018. http://www.eucast.org/clinical_break points/. Accessed 16 June 2018.

22. ANVISA. Agencia Nacional de Vigilância Sanitária (Nota técnica No 01/2013). Medidas de prevenção e controle de infecções por enterobactérias multirresistentes. 2013. http://portal.anvisa.gov.br/wps/wcm/ connect/ea4d4c004f4ec3b98925d9d785749fbd/Microsoft+Word++ NOTA+T\%C3\%89CNICA+ENTEROBACTERIAS+17+04+2013\%281\%29. pdf?MOD=AJPERES. Accessed 16 June 2018

23. Nordmann P, Poirel L, Dortet L. Rapid detection of carbapenemase-producing Enterobacteriaceae. Emerg Infect Dis. 2012;18(9):1503-7. https:// doi.org/10.3201/eid1809.120355.

24. Song W, Hong SG, Yong D, Jeong SH, Kim HS, Kim HS, et al. Combined use of the modified Hodge test and carbapenemase inhibition test for detection of carbapenemase-producing Enterobacteriaceae and metallo-betalactamase-producing Pseudomonas spp. Ann Lab Med. 2015;35(2):212-9. https://doi.org/10.3343/alm.2015.35.2.212

25. Magiorakos AP, Srinivasan A, Carey RB, Carmeli Y, Falagas ME, Giske CG, et al. Multidrug-resistant, extensively drug-resistant and pandrug-resistant bacteria: an international expert proposal for interim standard definitions for acquired resistance. Clin Microbiol Infect. 2012;18(3):268-81. https://doi.org/10.1111/j.1469-0691.2011.03570.x.

26. Seki LM, Pereira PS, de Souza MP, Conceicao Mde S, Marques EA, Porto $\mathrm{CO}$, et al. Molecular epidemiology of KPC-2-producing Klebsiella pneumoniae isolates in Brazil: the predominance of sequence type 437. Diagn Microbiol Infect Dis. 2011;70(2):274-7. https://doi.org/10.1016/j.diagm icrobio.2011.01.006.

27. Kulldorff M, Heffernan R, Hartman J, Assuncao R, Mostashari F. A spacetime permutation scan statistic for disease outbreak detection. PLoS Med. 2005;2(3):e59. https://doi.org/10.1371/journal.pmed.0020059.

28. Brockwell PJ, Davis RA. Time series: theory and methods. 2nd ed. Springer; 1991.

29. Shekhar S, Huang Y. Discovering spatial co-location patterns: a summary of results. In: Jensen CS, Schneider M, Seeger B, Tsotras VJ, editors. Advances in spatial and temporal databases. SSTD 2001. Lecture notes in computer science, vol. 2121. Springer; 2001. https://doi.org/10.1007/3540-47724-1_13.

30. Kistemann T, Dangendorf F, Krizek L, Sahl HG, Engelhart S, Exner M. GIS-supported investigation of a nosocomial Salmonella outbreak. Int J Hyg Environ Health. 2000;203(2):117-26. https://doi.org/10.1078/S14384639(04)70016-4.

31. Huang SS, Yokoe DS, Stelling J, Placzek H, Kulldorff M, Kleinman K, et al. Automated detection of infectious disease outbreaks in hospitals: a retrospective cohort study. PLoS Med. 2010;7(2):e1000238. https://doi.org/10. 1371/journal.pmed.1000238.

32. Tacconelli E, Sifakis F, Harbarth S, Schrijver R, van Mourik M, Voss A, et al. Surveillance for control of antimicrobial resistance. Lancet Infect Dis. 2018;18(3):e99-106. https://doi.org/10.1016/S1473-3099(17)30485-1.

33. Tseng WP, Chen YC, Chen SY, Chen SY, Chang SC. Risk for subsequent infection and mortality after hospitalization among patients with multidrug-resistant Gram-negative bacteria colonization or infection. Antimicrob Resist Infect Control. 2018;7:93. https://doi.org/10.1186/ s13756-018-0388-z. 
34. Blanco N, O'Hara LM, Harris AD. Transmission pathways of multidrugresistant organisms in the hospital setting: a scoping review. Infect Control Hosp Epidemiol. 2019;40(4):447-56. https://doi.org/10.1017/ice. 2018.359.

35. Sirijatuphat $R$, Sripanidkulchai $K$, Boonyasiri $A$, Rattanaumpawan $P$ Supapueng O, Kiratisin P, et al. Implementation of global antimicrobial resistance surveillance system (GLASS) in patients with bacteremia. PLoS ONE. 2018;13(1):e0190132. https://doi.org/10.1371/journal.pone.0190132.

36. Rodrigues C, Passet V, Rakotondrasoa A, Brisse S. Identification of Klebsiella pneumoniae, Klebsiella quasipneumoniae, Klebsiella variicola and related phylogroups by MALDI-TOF mass spectrometry. Front Microbiol. 2018;9:3000. https://doi.org/10.3389/fmicb.2018.03000.

37. Collins AS. Preventing health care-associated infections. In: Hughes RG, editor. Patient safety and quality: an evidence-based handbook for nurses. Advances in patient safety. Agency for Healthcare Research and Quality; 2008.

38. Shuai J, Buck P, Sockett P, Aramini J, Pollari F. A GIS-driven integrated real-time surveillance pilot system for national West Nile virus dead bird surveillance in Canada. Int J Health Geogr. 2006;5:17. https://doi.org/10. 1186/1476-072X-5-17.

39. Muenchow JSP, Brenning A. RQGIS: integrating R with QGIS for statistical geocomputing. R J. 2017;9(2):409-28. https://doi.org/10.32614/ RJ-2017-067.

40. Dicker RC CF, Koo D, Parrish RG. Principles of epidemiology in public health practice; an introduction to applied epidemiology and biostatistics. Department of Health and Human Services. Centers for Disease Control and Prevention (CDC), Office of Workforce and Career Development. Atlanta 30333: 2006.
41. Kohlmann R, Gatermann SG. Analysis and presentation of cumulative antimicrobial susceptibility test data-the influence of different parameters in a routine clinical microbiology laboratory. PLoS ONE. 2016;11(1):e0147965. https://doi.org/10.1371/journal.pone.0147965.

42. Clinical and Laboratory Standards Institute. M39-A4, analysis and presentation of cumulative antimicrobial susceptibility test data. 4th ed. Clinical and Laboratory Standards Institute; 2014.

43. Berends MSLC, Friedrich AW, Sinha BNM, Albers CJ, Glasner C. AMR: antimicrobial resistance analysis. R package version 0.9.0; 2019. https:// CRAN.R-project.org/package=AMR.

44. Lopez-Lozano JM, Lawes T, Nebot C, Beyaert A, Bertrand X, Hocquet $D$, et al. A nonlinear time-series analysis approach to identify thresholds in associations between population antibiotic use and rates of resistance. Nat Microbiol. 2019;4(7):1160-72. https://doi.org/10.1038/ s41564-019-0410-0.

45. Peng Gao DG, Liao K, Webb JJ, Cutter SL. Early detection of terrorism outbreaks using prospective space-time scan statistics. Prof Geogr. 2013;65(4):676-91. https://doi.org/10.1080/00330124.2012.724348.

46. Malizia N. Inaccuracy, uncertainty and the space-time permutation scan statistic. PLoS ONE. 2013;8(2):e52034. https://doi.org/10.1371/journal. pone.0052034.

\section{Publisher's Note}

Springer Nature remains neutral with regard to jurisdictional claims in published maps and institutional affiliations.
Ready to submit your research? Choose BMC and benefit from:

- fast, convenient online submission

- thorough peer review by experienced researchers in your field

- rapid publication on acceptance

- support for research data, including large and complex data types

- gold Open Access which fosters wider collaboration and increased citations

- maximum visibility for your research: over 100M website views per year

At BMC, research is always in progress.

Learn more biomedcentral.com/submissions 